Speeding and speed modification of older drivers: Does vehicle type make a difference?

Cull AW, Porter MM, Nakagawa S, Smith GA, Rapoport MJ, Marshall SC, Bédard M, Tuokko H, Vrkljan B, Naglie G, Myers AM, Mazer B. Speeding and Speed Modification of Older Drivers: Does Vehicle Type Make a Difference? Canadian Journal on Aging / La Revue canadienne du vieillissement. Cambridge University Press; 2020;39(3):385-92.

doi:10.1017/S0714980819000394

The published version of the manuscript can be found at Cambridge Journals who has copyright ownership:

https://www-cambridge-org.uml.idm.oclc.org/core/journals/canadian-journal-on-aging-la-revuecanadienne-du-vieillissement/article/speeding-and-speed-modification-of-older-drivers-doesvehicle-type-make-a-difference/A5041E1793E0CC11219A093235109164 


\section{Speeding and speed modification of older drivers: Does vehicle type make a difference?}

Andrew W. Cull, BSc ${ }^{1}$; Michelle M. Porter ${ }^{1}$, PhD; Satoru Nakagawa, PhD ${ }^{1}$; Glenys A. Smith, MSc ${ }^{1}$; Mark J. Rapoport, MD², FRCPC; Shawn C. Marshall, MD, MSc, FRCPC ${ }^{3}$; Michel Bédard, PhD4; Holly Tuokko, PhD ${ }^{5}$; Brenda Vrkljan, PhD ${ }^{6}$; Gary Naglie, MD, FRCPC ; Anita M. Myers, $\mathrm{PhD}^{8}$; Barbara Mazer, $\mathrm{PhD}^{9}$

${ }^{1}$ Faculty of Kinesiology and Recreation Management, University of Manitoba, Winnipeg, MB, Canada, R3T 2N2; ${ }^{2}$ Department of Psychiatry, University of Toronto, Toronto, ON; ${ }^{3}$ Ottawa Hospital Research Institute, University of Ottawa, Ottawa, ON; ${ }^{4}$ Centre for Research on Safe Driving, Lakehead University, Thunder Bay, ON; ${ }^{5}$ Centre on Aging, University of Victoria, Victoria, BC; ${ }^{6}$ School of Rehabilitation Science, McMaster University, Hamilton, ON;

${ }^{7}$ Department of Medicine and Rotman Research Institute, Baycrest Health Sciences, Research Department, Toronto Rehabilitation Institute, University Health Network, Department of Medicine and Institute of Health Policy, Management and Evaluation, University of Toronto, Toronto, ON; ${ }^{8}$ School of Public Health \& Health Systems, University of Waterloo, Waterloo, ON; ${ }^{9}$ School of Physical \& Occupational Therapy, McGill University, Centre for Interdisciplinary Research in Rehabilitation of Greater Montreal

\section{Corresponding Author:}

Michelle M. Porter, PhD, Professor

Faculty of Kinesiology and Recreation Management

University of Manitoba

Winnipeg, MB

CANADA R3T 2N2

(204) 474-8795 michelle.porter@umanitoba.ca 


\section{ACKNOWLEDGEMENTS}

This study was funded by AUTO21, Manitoba Centres of Excellence Fund, and a Team Grant from the Canadian Institutes of Health Research (CIHR) entitled "The CIHR Team in Driving in Older Persons (Candrive II) Research Program" (grant 90429). Additional support was provided by the Ottawa Hospital Research Institute and the Toronto Rehabilitation Institute, University Health Network, and the University of Manitoba. Dr. Gary Naglie is supported by the George, Margaret and Gary Hunt Family Chair in Geriatric Medicine, University of Toronto. Dr. Michel Bédard was supported by a Canada Research Chair in Aging and Health during the development phase of this study. None of the funders were involved in any aspects of the study or the manuscript.

The Candrive Investigators thank the Candrive cohort study participants for their dedication. Without their commitment, this publication would not have been possible.

The Candrive Investigators thank Lynn MacLeay, Candrive Program Manager, for her role in managing and operationalizing the study for the Canadian sites. The Candrive Investigators thank the Research Associates for their dedication and contribution to the success of the study (in order of participant recruitment); Candrive Research Coordinators; Jennifer Biggs and Anita Jessup (Ottawa Coordinating Centre), Phyllis McGee (Victoria), Linda Johnson and Joanne Parsons (Winnipeg), Novlette Fraser and Sue Woodard (Toronto), Sheila Garrett (Hamilton), Felice Mendelsohn, Minh-Thy DinhTruong, Suzie Schwartz and Rivi Levkovich (Montreal), and Laura Morrison, Hillary Maxwell (Thunder Bay).

The Candrive Investigators thank the additional support staff for their dedication and contribution to the success of the study: Kelly Weegar and Chantal Rockwell (Ottawa). The Candrive investigators wish to thank the following individuals for their work associated with the in-vehicle driving data: Melissa Smith, Sandra Webber and Maureen Babb (Winnipeg). 


\begin{abstract}
The purpose of this study was to examine whether vehicle type based on size (car versus other = truck/van/SUV) had an impact on the speeding, acceleration, and braking patterns of older male and female drivers (70 years and older) from a Canadian longitudinal study. The primary hypothesis was that older adults driving larger vehicles (e.g., trucks, SUVs or vans) would be more likely to speed than those driving cars. Participants $(n=493)$ had a device installed in their vehicles that recorded their everyday driving. The findings suggest that the type of vehicle driven had little or no impact on percent of time speeding or on the braking and accelerating patterns of older drivers. Given that the propensity for exceeding the speed limit was high among these older drivers, regardless of vehicle type, future research should examine what effect this behaviour has on older driver road safety.
\end{abstract}

Keywords: Speeding, Automobile Driving, Older Drivers, Acceleration, Braking, Aging 
Older adults rely on motor vehicles as their main form of transportation in Canada, with the majority driving their own vehicles (Turcotte, 2012). Other forms of transportation (public transit, walking or biking, taxis or accessible transit) are much less likely to be used (Turcotte, 2012). For the older population, driving represents independence and is important to quality of life (Dickerson et al., 2007).

While most older drivers are safe drivers, the effects of collisions, whether at-fault or not, can be severe. Older drivers tend to experience greater injuries and fatalities in motor vehicle collisions due to increased fragility with age (Meuleners, Harding, Lee, \& Legge, 2006; Mitchell, 2013).

Several research studies have investigated ways to enhance the safety of older drivers due to: 1) the importance of continuing to drive in older adulthood, 2) possible functional and medically related changes with aging in driving performance, as well as 3) the increased risk of injury. This includes studies on screening for medical fitness to drive, interventions to improve their behind-the-wheel skills, as well as research that has examined how older adults drive and which behaviours increase their crash risk. Speeding, as a driving behaviour, has an effect on the propensity for crashing, as well as the severity of crashes (European Conference of Ministers of Transport, 2006). In older drivers, speeding has been identified as a factor leading to more serious injuries with motor vehicle collisions (Boufous, Finch, Hayen, \& Williamson, 2008). 
Within our society, there is a common assumption that older adults drive too slowly (Joanisse, Gagnon, \& Voloaca, 2012). This is supported by self-report studies which have suggested that older drivers are more likely to avoid high speed conditions (Motak, Gabaude, Bougeant, \& Huet, 2014; Siren \& Meng, 2013). However, this has not always been evident in studies that have objectively measured speeding behaviours in older drivers. Until relatively recently, few studies had objectively monitored the actual speed or speed modification (acceleration and braking) behaviours of older drivers. Some initial work suggested that older drivers have a longer deceleration time and distance, and drive more slowly than younger drivers (Nakagawa, Kriellaars, Blais, Montufar, \& Porter, 2006; Porter \& Whitton, 2002). However, these early studies also showed that older drivers do exceed the speed limit. Other, more recent, but still relatively small studies, have also found that older drivers do, in fact, drive over the speed limit (Choukou, 2014; Crizzle \& Myers, 2013; Porter \& Ash, 2008; Porter, 2013; Vlahodimitrakou et al., 2013).

Within the road safety literature, various theories have been posited to explain driver decision making, particularly regarding speed. Fuller (2005) proposed that drivers try to achieve a balance between task difficulty and capability, such that when task difficulty increases a driver is more likely to reduce their speed, which is an operational decision. In Fuller's driving model, other factors were identified that can affect the task demand, including the presence of other road users. Fleiter, Lennon and Watson (2010) have qualitatively explored the impact of other people (not just road users) on speeding, and found that there are a variety of "others" (e.g., passengers, family, peers, etc.) that can affect speeding, in both positive and negative ways. 
Enforcement as well as various road features (e.g., width, surface, number of lanes, straightness, proximity of trees, etc.) may also influence speeding behavior (Aarts, Brandenburg, and Van Nes, 2011).

Another factor that Fuller (2005) identified that could influence the tendency for speeding is the type of vehicle driven. Elements of importance include: performance characteristics, mass and height. For example, McCartt and $\mathrm{Hu}$ (2017) found that vehicle power was positively associated with an increase in exceeding the speed limit, when examining roadways in Northern Virginia. Padget, Knapp, and Thomas (2001) also found that sport utility vehicles (SUVs) were driven faster in winter conditions. However, that same study did not find that larger vehicles like SUVs were driven faster in "normal conditions". In a driving simulator study, younger drivers were found to drive faster when their seat height (distance off the ground) was manipulated to replicate a sport utility vehicle (SUV) height as compared to a sports car height (Rudin-Brown, 2005). The effect of vehicle seat height on the processing of visual information to determine a "comfortable speed", although not always perceptible to the drivers, could have serious road safety implications.

The objective of this study, with a large sample of older Canadian drivers, was to determine whether the type of vehicle affects older drivers' everyday driving behaviour, specifically speeding, accelerating and braking. In this study we focused on vehicle size - comparing smaller vehicles (i.e., cars) with larger vehicles that generally have higher seat heights (i.e., trucks, 
SUVs, vans). The primary hypothesis was that older adults driving larger vehicles would speed more than those driving smaller vehicles.

\section{Methods}

\section{Longitudinal Study}

Data for this study came from the Candrive cohort study (Marshall et al., 2013). Participants underwent annual assessments and also had a device installed in their vehicle to monitor their everyday driving patterns. Across seven sites in Canada (Ottawa, Montreal, Toronto, Hamilton, Thunder Bay, Winnipeg and Victoria) 928 drivers 70 years and older were recruited via newspaper article and other media reports, posters, and retiree newsletters, etc. There were several inclusion criteria for enrollment in the longitudinal study: driving at least 4 times per week, having a driver's licence for at least 1 year, living within $50 \mathrm{~km}$ of the test site, and being in their province of residence for at least 10 months of the year.

All participants' vehicles were equipped with an OttoView-CD Autonomous Data Logging Device (Persen Technologies Inc.) that captured data at a rate of $1 \mathrm{~Hz}$. The device included a GPS receiver, and an OBDII diagnostics receiver. The GPS receiver captured the position of the vehicle (as longitude/latitude), speed ( $\mathrm{km} / \mathrm{h})$, and Greenwich Mean Time (GMT). The software that comes with the device also provides geographic information system (GIS) data (e.g., speed limits for the roadways within the cities of the test sites). Participants who were not the sole driver of the vehicle also had a radio frequency antenna and unique identification fob installed to identify their trips. More details on the device and resulting data are available in Porter et al. (2015). 


\section{Participants}

The data from participants were included in these analyses, provided each participant had at least 25 days (and a $100 \mathrm{~km}$ ) of usable driving data, between May and September in year 1 of the study. Also, during those 25 days they could not have changed vehicles. This time frame was chosen to avoid the winter months as driving patterns have been shown to change in winter conditions (Padget et al., 2001). For those participants with a full 5 months (MaySeptember) of usable data, a random sample of 25 days of data was selected. Figure 1 shows the participant selection process.

\section{Data and Statistical Analyses}

Vehicle Classification. The participant vehicle data included the year, make, and general model. Since only the general model was known, the exact performance characteristics of each vehicle could not be determined because these vary by model sub-types. In this study, vehicles were classified using the 2014 Canada Fuel Consumption Guide (Natural Resources Canada, 2014). Because we were primarily interested in larger versus smaller vehicles, we combined all cars into one category, and then combined all other vehicles (trucks, SUVs, and vans) into an "other" category.

Speeding. Speeding was defined as occurring at any point of time the GPS speed was greater than the posted roadway speed limit reported from the Candrive DTS software. Speeding, above each speed limit $(10,20,30,40,50,60,70,80,90,100,110 \mathrm{~km} / \mathrm{h}) \mathrm{by} \geq 5 \mathrm{~km} / \mathrm{hr}, \geq 10$ $\mathrm{km} / \mathrm{hr}$, or $\geq 15 \mathrm{~km} / \mathrm{hr}$, was normalized to the total percentage of driving time at each speed limit. 
Acceleration and Braking. Acceleration values were calculated using the GPS $1 \mathrm{~Hz}$ speed data using the backward difference method in Eq. (1), where $k$ is the current value and $k+1$ is the next time step. G force was obtained from equation (1) by dividing by acceleration due to gravity $\left(9.81 \mathrm{~m} / \mathrm{s}^{2}\right)$. A value of $\geq 0.27369795918 \mathrm{~g}$ or $\leq-0.27369795918 \mathrm{~g}$ was considered to be a hard acceleration (or braking) event (Jun, Ogle, and Guensler et al., 2007).

$$
\text { acceleration }_{k+1}=\frac{\left(\text { speed }_{k+1}-\text { speed }_{k}\right)}{\left(\text { time }_{k+1}-\text { time }_{k}\right)}
$$

In order to analyse the hard braking and accelerating events, the values were normalized to the total distance travelled during the appropriate time period, as well as number of stops for braking events.

Statistical analyses. Multiple linear regression analyses were performed with proportion of time speeding for each posted speed limit as the dependent variables. Speed limits with insufficient numbers of cases (i.e., $10 \mathrm{~km} / \mathrm{hr}, 20 \mathrm{~km} / \mathrm{hr}$ and $110 \mathrm{~km} / \mathrm{hr}$ ) were not analysed. Independent variables were vehicle type, age and gender. As for acceleration, normality was tested and corrected through power transforms where applicable.

To determine which factors were associated with hard $\mathrm{g}$ force events per $\mathrm{km}$ and per stop, multiple linear regressions were performed using the independent variables of age, gender, and 
vehicle type. Normality was tested using the Shapiro-Wilks test and a Yeo Johnson power transform was used to transform the data, when the data were not normally distributed. Throughout all these exploratory analyses, $p<0.05$ was deemed significant using $R$ ( $R$ Core Team, 2014) and SigmaPlot (Systat Software, San Jose, CA).

\section{Results}

\section{Participants}

In total, 493 participants ( 287 men and 206 women) met the criteria for these analyses. There were 396 driving cars and 97 other vehicles. These participants ranged in age from 70 to 93 years of age; with a median age of 77 years. Table 1 shows the characteristics of the participants by vehicle type. There was a higher percentage of men driving other vehicles. Those driving cars were significantly older than those driving other vehicles. Other significant differences between the two vehicle type drivers were in self-reported number of kilometers driven in a year, as well as types of licenses, both of which could be affected by the age and/or gender of the drivers. There were no differences in numbers of medical conditions, their performance on the Trails B test, or in the percent of time driving at night.

\section{Speeding}

All 493 participants exceeded the posted speed limit by $5 \mathrm{~km} / \mathrm{h}$ at some point. The percent of participants speeding by at least $5 \mathrm{~km} / \mathrm{h}$ can be found in Table 2 . For all speed limits (except $110 \mathrm{~km} / \mathrm{hr}$ where only 5 participants had driven on this type of roadway) the vast majority of 
individuals did speed at some point. For the $50 \mathrm{~km} / \mathrm{hr}$ zone, $99.8 \%$ of individuals sped some of the time.

Descriptive statistics on the proportion of time spent speeding at each speed zone (using thresholds of 5, 10 or $15 \mathrm{~km} / \mathrm{hr}$ over the speed limit) are found in Table 3. As indicated by the standard deviations relative to mean values, it can be seen there is a lot of variability between participants. For all speed limits there were individuals who did not speed at any time. At the other end of the range, some drivers were speeding $100 \%$ of the time at several speed limits $(20,30,40,60,70,80 \mathrm{~km} / \mathrm{hr})$.

Significant multiple regression models for percent of time speeding are shown in Tables 4, 5, and 6. Similar results were found for all speeding thresholds $(5,10$, and $15 \mathrm{~km} / \mathrm{hr})$. In general, vehicle type (car or other) was not a significant factor for explaining the percent of time speeding. Where it was significant (speed limit of $80 \mathrm{~km} / \mathrm{hr}$, threshold of 10 and $15 \mathrm{~km} / \mathrm{hr}$ ) driving a car meant speeding more than the other type of vehicle. Both age and gender were significant in several models. Older age was associated with a lower percent of time speeding , whereas being male was associated with a greater percent of time speeding. Overall, the models did not explain much of the variance in percent of time speeding (adjusted $R^{2}$ values ranged from 0.013 to 0.085$)$, with the most predictive model for both speeding thresholds occurring on roadways with speed limits of $100 \mathrm{~km} / \mathrm{hr}$. For all of these models, age and gender were significant, but vehicle type was not. 


\section{Acceleration and braking}

The results of the multiple regression for hard brakes per km showed that there were significant effects for age (older drivers having more instances, $p=0.002$ ), gender (women having more hard brake events than men, $p=0.004$ ), and vehicle class (cars having more than other vehicles, $p=0.009$ ). The adjusted $R^{2}$ was found to be 0.060 . The same analysis, with hard brakes per stop as the dependent variable, did not have any significant predictors.

For hard accelerations per $\mathrm{km}$, age (older drivers having more incidents, $p=0.037$ ) and vehicle class (cars having more than other vehicles, $p=0.005$ ) were significant predictors with an adjusted $R^{2}$ value of 0.027 . For hard accelerations per stop, vehicle class (cars having more than other vehicles, $p=0.004$ ) was a significant predictor, and the model had an adjusted $R^{2}$ of 0.035 .

\section{Discussion}

In this study, involving a large sample of older Canadian drivers, we explored the effects of vehicle type on how older drivers speed and modify their speed, using a device that objectively captured their everyday driving. While older adults were speeding quite frequently, whether a threshold of $5 \mathrm{~km} / \mathrm{hr}, 10 \mathrm{~km} / \mathrm{hr}$, or $\geq 15 \mathrm{~km} / \mathrm{hr}$ was used, there were very small and limited effects of the size of the vehicle. Overall the statistical models explained less than $10 \%$ of the variance in speeding and speed modification, and in some cases the effect of vehicle type was the opposite of what was hypothesized. 
Where there were significant effects of vehicle type, age and gender on the number of hard accelerations and braking episodes, it is unclear how much of this very small effect can be attributed to these particular factors. It is possible that something else about driving cars versus other vehicles, men versus women, or younger versus older drivers also contributes to these findings. For example, it could be that drivers might choose to drive a specific type of vehicle due to health status, ease of ingress/egress, or feelings of safety. In addition, those driving other vehicles (SUV or truck) might adopt different driving styles to conserve gas, or they might drive on different types of roadways where fewer hard braking episodes are required (e.g., no traffic lights). This might be why there were no significant factors explaining hard brakes per stop, but there were for hard brakes per km.

In this study we are limited to knowing the make and model of the vehicle that participants drove, but we do not know why they chose to drive those types of vehicle. This research on vehicle type is also limited to older drivers and it is not possible to extrapolate these findings to younger drivers who might have different speeding behaviours. Other limitations of the research, because we did not video record trips, include not knowing whether the drivers had passengers in the vehicles with them, and we also are unable to assess the trips for the traffic density, and the effects this might have had on driving patterns. It is also possible that participants in this study and their driving patterns are not representative of all older drivers. It has been found, though, that many of the Candrive sample's characteristics are very closely aligned with older drivers across Canada in the Canada Community Health Survey (Gagnon et al., 2013). 
An interesting finding from this large cohort of older drivers is their propensity for speeding. The extent of speeding based on the number of participants who were speeding was generally higher on low speed roadways. This effect is similar to Feng (2001) who reported low compliance with speed limits on roadways with lower speed limits. However, the percent of time speeding on lower speed limit roadways was lower than on higher speed roadways. It is likely that the percent of time is affected by the fact that there is more stop and go driving on low speed roadways (e.g., stop signs), and so more of the driving time on low speed roadways is taken up by accelerating up to a stable speed as well as decelerating. On high speed roadways drivers are likely driving at stable speeds more of the time.

All 493 participants in this study were found to be speeding at some time during the 25 days which were considered in these analyses. This supports previous studies that involved smaller sample sizes and/or shorter measurement time frames (Choukou et al., 2014; Crizzle \& Myers, 2013; Nakagawa et al., 2006; Porter \& Ash, 2008; Porter \& Whitton, 2002; Porter, 2013; Vlahodimitrakou et al., 2013). Given the fact that so many were speeding, it could be difficult to specifically find an effect of the type of vehicle. However, there was quite a bit of variability between individuals in the proportion of time that they did speed, and there were other factors, such as age and gender, that seemed to affect speeding more than vehicle type. The small effects of age and gender showed that the oldest drivers and women were less likely to speed. The fact that the type of vehicle driven was not a factor in explaining the percent of time speeding is supported by previous studies that have used observational approaches to 
examine vehicle type, without examining the characteristics of the drivers (Hallmark, Knapp, \& Grant, 2004; Padget et al., 2001).

As mentioned earlier, there are many reasons for speeding. Driving in a familiar environment could be a factor (Charlton \& Starkey, 2013). In a simulator study examining extended practice over 3 months, drivers tended to increase their speed in scenarios that became familiar (Charlton \& Starkey, 2013). As the current study examined this behaviour in real world driving, it is reasonable to presume that the majority of their driving trips were on familiar routes. However, we did not examine every trip made for the exact location relative to their typical driving, so we do not know if all driving analyzed here was made on familiar routes.

Another reason for speeding is related to the social context. For example, there is a "social contagion" for speeding: meaning we tend to adjust our speed to the surrounding traffic (Feng, 2001). Also, most drivers seem to perceive that other drivers drive faster than they do (Walton \& Bathurst, 1998). More specifically, other drivers can directly pressure those around them to speed by tailgating or flashing their lights (Feng, 2001). Older drivers have reported feeling pressured to go with the flow of the traffic rather than remaining at or below the speed limit, even while having a special device in their vehicle that warned them about their speeding (Porter \& Ash, 2008). Homogeneity of speed across all drivers on a specific roadway is important for safety, with large differences between speeds of vehicles creating a safety hazard (Aarts et al., 2011), so there is logic in their speed choices if almost everyone else is speeding (European Conference of Ministers of Transport, 2006; Feng, 2001). Research has shown that 
younger drivers do speed more than older drivers (Molnar et al., 2018; Nakagawa et al., 2006;

Porter \& Whitton, 2002). The problem in older drivers trying to "keep up" with younger drivers is that older drivers might misjudge their ability to drive at faster speeds, thus raising their crash risk. The fact that they are more likely to be seriously injured or killed, if in a collision, makes this type of behaviour potentially even more risky for an older driver. At present it is unclear what the potential implications are for the safety of these older drivers related to speeding and hard brakes or accelerations. Future analyses with naturalistic datasets will allow for examining the speed and speed modification patterns of older drivers and their risk for collisions.

\section{Conclusions}

The results of this study showed that vehicle type seems to have little to no impact on the propensity for older drivers to speed or make hard brakes / accelerations. Speeding $(5 \mathrm{~km} / \mathrm{hr}$, $10 \mathrm{~km} / \mathrm{hr}$ or $\geq 15 \mathrm{~km} / \mathrm{hr}$ ) was prevalent in these older drivers. Future research is needed to determine what effect these common driving behaviours (speeding or speed modification) have on the safety of older drivers. 


\section{References}

Aarts, L., Brandenburg, S., Van Nes, N. (2011). The influence of environmental factors on speed choice. 2011 IEEE Forum on Integrated and Sustainable Transportation Systems, art. no. 5973632, 91-96.

Boufous, S., Finch, C., Hayen, A., \& Williamson, A. (2008). The impact of environmental, vehicle and driver characteristics on injury severity in older drivers hospitalized as a result of a traffic crash. Journal of Safety Research, 39, 65-72. doi:10.1016/j.jsr.2007.10.010

Charlton, S. G., \& Starkey, N. J. (2013). Driving on familiar roads: Automaticity and inattention blindness. Transportation Research Part F-Traffic Psychology and Behaviour, 19, 121133. doi:10.1016/j.trf.2013.03.008

Choukou, M. A., Bluteau, C., Germain-Robitaille, M., Simoneau, M., Lavallière, M., Moskowicz, T., Laurendeau, D., Teasdale, N. (2014). Naturalistic study of stop-controlled intersections negotiation and respect for speed limits in drivers aged 65 and over. Recherche Transportation Securite, 30, 271-281.

Crizzle, A. M., \& Myers, A. M. (2013). Examination of naturalistic driving practices in drivers with Parkinson's disease compared to age and gender-matched controls. Accident Analysis and Prevention, 50, 724-731. doi:10.1016/j.aap.2012.06.025

Dickerson, A. E., Molnar, L. J., Eby, D. W., Adler, G., Bedard, M., Berg-Weger, M., ... Trujillo, L. (2007). Transportation and aging: a research agenda for advancing safe mobility. The Gerontologist, 47, 578-590.

European Conference of Ministers of Transport (2006). Speed Management.

Feng, C. (2001). Synthesis of studies on speed and safety. Transportation Research Record: Journal of the Transportation Research Board, 1779, 86-92. doi:DOI: 10.3141/1779-12

Fleiter, J. J., Lennon, A., Watson, B. (2010). How do other people influence your driving speed? Exploring the 'who' and the 'how' of social influences on speeding from a qualitative perspective. Transportation Research Part F: Traffic Psychology and Behaviour, 13, 4962. 
Fuller, R. (2005). Towards a general theory of driver behaviour. Accident Analysis and Prevention, 37, 461-472.

Gagnon, S., Marshall, S. Kadulina, Y. \& Stinchcombe, A., Bédard, M., Gélinas ... Vrkljan, B. (2016). CIHR Candrive Cohort Comparison with Canadian Household Population Holding Valid Driver's Licenses. Canadian Journal on Aging / La Revue canadienne du vieillissement. 35. 99-109. doi:10.1017/S0714980816000052.

Hallmark, S. L., Knapp, K. K., \& Grant, C. D. (2004). Evaluating speed differences between cars, light-duty trucks, and vans for emissions modeling. Journal of Transportation Engineering-ASCE, 130, 814-817. doi:Doi 10.1061/(Asce)0733-947x(2004)130:6(814)

Joanisse, M., Gagnon, S., \& Voloaca, M. (2012). Overly cautious and dangerous: An empirical evidence of the older driver stereotypes. Accident Analysis and Prevention, 45, 802-810. doi:10.1016/j.aap.2011.11.002

Jun, J., Ogle, J., \& Guensler, R. (2007). Relationships between crash involvement and temporal spatial driving behavior activity patterns: Use of data for vehicles with global positioning systems. Transportation Research Record: Journal of the Transportation Research Board, 2019, 246-255. http://doi.org/10.3141/2019-29

Marshall, S. C., Man-Son-Hing, M., Bedard, M., Charlton, J., Gagnon, S., Gelinas, I., . . . Woolnough, A. (2013). Protocol for Candrive II/Ozcandrive, a multicentre prospective older driver cohort study. Accident Analysis and Prevention, 61, 245-252. doi:S00014575(13)00046-8 [pii];10.1016/j.aap.2013.02.009 [doi]

McCartt, A. T., \& Hu, W. (2017). Effects of vehicle power on passenger vehicle speeds. Traffic Injury Prevention, 18, 500-507. doi:10.1080/15389588.2016.1241994

Meuleners, L. B., Harding, A., Lee, A. H., \& Legge, M. (2006). Fragility and crash overrepresentation among older drivers in Western Australia. Accident Analysis and Prevention, 38, 1006-1010. doi:10.1016/j.aap.2006.04.005

Mitchell, C. G. B. (2013). The licensing and safety of older drivers in Britain. Accident Analysis and Prevention, 50, 732-741. doi:10.1016/j.aap.2012.06.027

Molnar, L.J., Eby, D.W., Bogard, S.E., LeBlanc, D.J., Zakrajsek, J.S. (2018) Using naturalistic driving data to better understand the driving exposure and patterns of older drivers. Traffic Injury Prevention, 19, S83-88. doi:10.1080/15389588.2017.1379601. 
Motak, L., Gabaude, C., Bougeant, J. C., \& Huet, N. (2014). Comparison of driving avoidance and self-regulatory patterns in younger and older drivers. Transportation Research Part FTraffic Psychology and Behaviour, 26, 18-27. doi:10.1016/j.trf.2014.06.007

Nakagawa, S., Kriellaars, D., Blais, C., Montufar, J., \& Porter, M. M. (2006). Speed and acceleration patterns of younger and older drivers. Canadian Multidisciplinary Road Safety Conference, Winnipeg, MB, Canada.

Natural Resources Canada (2014). 2014 Fuel Consumption Guide.

Padget, E. D., Knapp, K. K., \& Thomas, G. B. (2001). Investigation of winter-weather speed variability in sport utility vehicles, pickup trucks, and passenger cars. Transportation Research Record: Journal of the Transportation Research Board, 1779, 116-124.

Porter, M. M. (2013). Older driver training using video and global positioning system technology--a randomized controlled trial. Journals of Gerontology Part A, 68, 574-580. doi:gls160 [pii];10.1093/gerona/gls160 [doi]

Porter, M. M., \& Ash, H. (2008). The effect of a new road safety device with auditory alerts on older drivers. Canadian Multidisciplinary Road Safety Conference.

Porter, M. M., Smith, G. A., Cull, A. W., Myers, A. M., Bedard, M., Gelinas, I., . . Vrkljan, B. H. (2015). Older driver estimates of driving exposure compared to in-vehicle data in the Candrive II study. Traffic Injury Prevention, 16, 24-27. doi:10.1080/15389588.2014.894995

Porter, M. M., \& Whitton, M. J. (2002). Assessment of driving with the global positioning system and video technology in young, middle-aged, and older drivers. Journals of Gerontology Part A, 57, 578-582.

Rudin-Brown, C. M. (2005). Vehicle height affects drivers' speed perception-Implications for rollover risk. Transportation Research Record: Journal of the Transportation Research Board, 1899, 84-89.

Siren, A., \& Meng, A. (2013). Older drivers' self-assessed driving skills, driving-related stress and self-regulation in traffic. Transportation Research Part F-Traffic Psychology and Behaviour, 17, 88-97. doi:10.1016/j.trf.2012.10.004 


\section{Older driver speeding and vehicle type}

Turcotte, M. (2012). Profi le of seniors' transportation habits. Canadian Social Trends, Catalogue no. 11-008, 16.

Vlahodimitrakou, Z., Charlton, J. L., Langford, J., Koppel, S., Di, S. M., Macdonald, W., . . . Marshall, S. (2013). Development and evaluation of a driving observation schedule (DOS) to study everyday driving performance of older drivers. Accident Analysis and Prevention, 61, 253-260. doi:S0001-4575(13)00125-5 [pii];10.1016/j.aap.2013.03.027 [doi]

Walton, D., \& Bathurst, J. (1998). An exploration of the perceptions of the average driver's speed compared to perceived driver safety and driving skill. Accident Analysis and Prevention, 30, 821-830. 


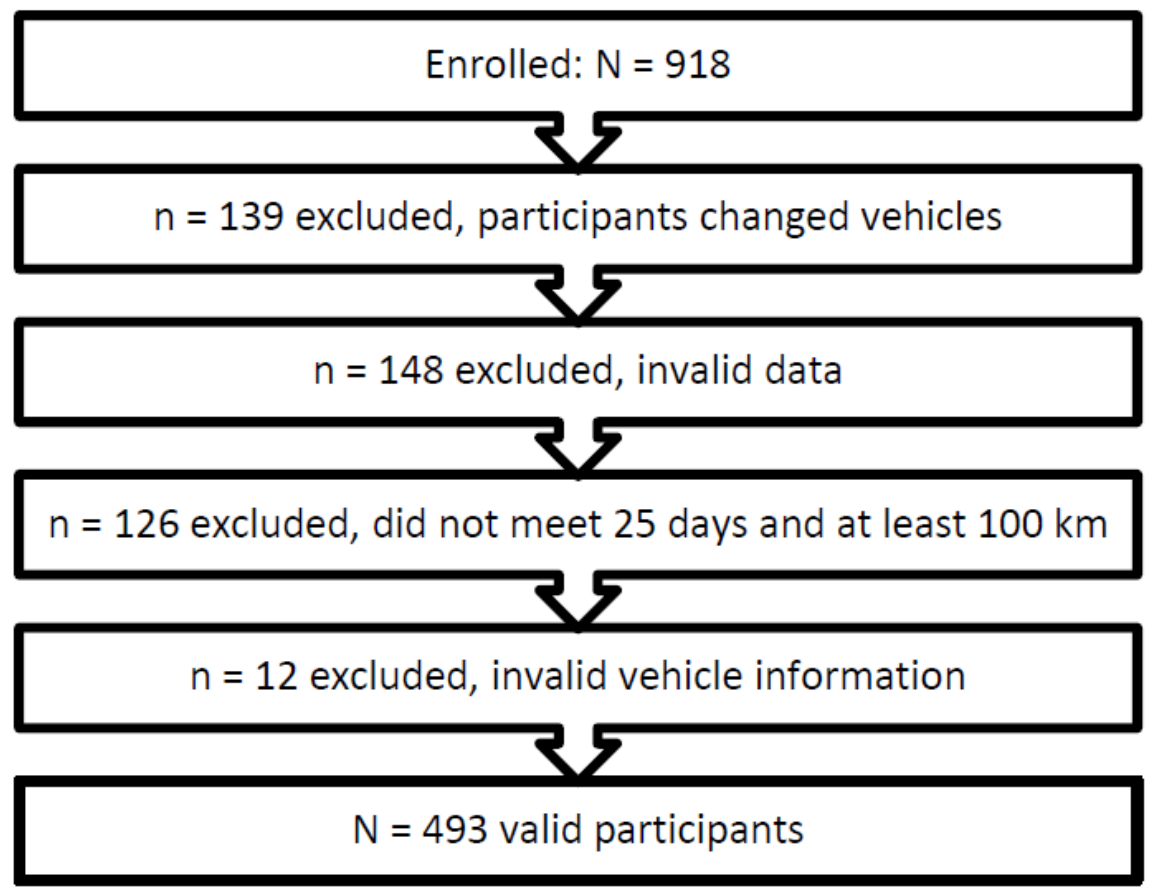

Figure 1. Flowchart illustrating participant selection. 
Table 1. Participant characteristics by vehicle type.

\begin{tabular}{|c|c|c|}
\hline Characteristic & Car $(n=396)$ & Other $(n=97)$ \\
\hline Age (years, $\mathrm{M} \pm \mathrm{SD}$ )* & $77.2 \pm 4.9$ & $75.9 \pm 4.1$ \\
\hline Gender ( $\%$ male $)^{*}$ & 53.5 & 77.3 \\
\hline Trails B time (sec) & $101.9 \pm 75.9$ & $103.1 \pm 54.2$ \\
\hline Number of medical conditions ( $\mathrm{M} \pm \mathrm{SD}$ ) & $7.6 \pm 3.5$ & $7.5 \pm 3.3$ \\
\hline \multicolumn{3}{|l|}{ Self-reported \# of km driven $(\mathrm{km})^{*}$} \\
\hline 1000 to 5000 & 15.7 & 6.2 \\
\hline 5001 to 10000 & 31.4 & 17.5 \\
\hline 10001 to 15000 & 26.6 & 29.9 \\
\hline 15001 to 20000 & 13.4 & 21.6 \\
\hline$>20,000$ & 11.9 & 24.8 \\
\hline \multicolumn{3}{|l|}{ License class (\%)* } \\
\hline 5 (regular) & 86.4 & 73.4 \\
\hline 6 (motorcycle) & 0.5 & 0.0 \\
\hline Other classes (buses, trucks, taxis, etc.) & 13.2 & 26.6 \\
\hline Percent of driving at night & $6.9 \pm 5.9$ & $7.4 \pm 8.2$ \\
\hline
\end{tabular}




\section{Older driver speeding and vehicle type}

Table 2. Speeding behaviour by roadway speed limit.

\begin{tabular}{l|lll} 
Speed Limit $(\mathrm{km} / \mathrm{h})$ & $\begin{array}{l}\text { Number of participants } \\
\text { driving on road way with }\end{array}$ & $\begin{array}{l}\text { Number of participants } \\
\text { who exceeded speed }\end{array}$ & \\
& specific speed limit & limit by at least $5 \mathrm{~km} / \mathrm{h}$ & \\
\hline 20 & 74 & 65 & 12.2 \\
30 & 321 & 316 & 1.6 \\
40 & 422 & 412 & 2.4 \\
50 & 493 & 492 & 0.2 \\
60 & 448 & 433 & 3.4 \\
70 & 458 & 368 & 19.7 \\
80 & 414 & 358 & 13.5 \\
90 & 284 & 212 & 25.4 \\
100 & 372 & 304 & 18.3 \\
110 & 5 & 2 & 60.0
\end{tabular}


Table 3. Percent of time exceeding the speed limit. Means and standard deviations (SD) are reported for each speed limit.

\begin{tabular}{|c|c|c|c|c|}
\hline $\begin{array}{l}\text { Speed Limit } \\
(\mathrm{km} / \mathrm{h})\end{array}$ & $\begin{array}{l}\text { Number of } \\
\text { participants } \\
\text { driving on road } \\
\text { way with specific } \\
\text { speed limit }\end{array}$ & $\begin{array}{l}\text { Mean ( } \pm \text { SD) \% } \\
\text { time speeding, } \\
5 \mathrm{~km} / \mathrm{hr} \\
\text { threshold }\end{array}$ & $\begin{array}{l}\text { Mean ( } \pm \text { SD) \% } \\
\text { time speeding, } \\
10 \mathrm{~km} / \mathrm{hr} \\
\text { threshold }\end{array}$ & $\begin{array}{l}\text { Mean ( } \pm \text { SD) \% } \\
\text { time speeding, } \\
15 \mathrm{~km} / \mathrm{hr} \\
\text { threshold }\end{array}$ \\
\hline 20 & 74 & $39.5 \pm 38.6$ & $29.8 \pm 37.3$ & $22.2 \pm 33.6$ \\
\hline 30 & 321 & $40.8 \pm 32.8$ & $31.2 \pm 31.8$ & $19.4 \pm 27.4$ \\
\hline 40 & 422 & $17.5 \pm 16.6$ & $9.0 \pm 13.0$ & $4.3 \pm 9.3$ \\
\hline 50 & 493 & $6.8 \pm 6.6$ & $3.6 \pm 5.5$ & $1.9 \pm 4.7$ \\
\hline 60 & 448 & $11.3 \pm 13.4$ & $6.2 \pm 11.6$ & $3.8 \pm 10.2$ \\
\hline 70 & 458 & $11.2 \pm 15.7$ & $6.9 \pm 13.0$ & $3.8 \pm 9.7$ \\
\hline 80 & 414 & $15.1 \pm 17.6$ & $7.6 \pm 12.5$ & $6.7 \pm 9.2$ \\
\hline 90 & 284 & $16.6 \pm 19.0$ & $8.7 \pm 13.1$ & $3.3 \pm 7.3$ \\
\hline 100 & 372 & $21.7 \pm 23.5$ & $11.3 \pm 17.1$ & $4.6 \pm 10.2$ \\
\hline 110 & 5 & $30.6 \pm 42.8$ & $15.9 \pm 34.8$ & $12.2 \pm 27$ \\
\hline
\end{tabular}

Table 4. Results of the significant multiple regressions models of percent time speeding for each speed limit with age, gender and vehicle class (car or other) as predictor variables, with $5 \mathrm{~km} / \mathrm{hr}$ as the threshold for speeding. Note: ${ }^{*} \mathrm{p}<0.05, * * \mathrm{p}<0.01, * * * \mathrm{p}<0.001$

\begin{tabular}{l|lll} 
Speed Limit $(\mathrm{km} / \mathrm{h})$ & $\mathrm{n}$ & Adjusted $\mathrm{R}^{2}$ & Significant predictors \\
\hline 50 & 493 & 0.018 & Age*** \\
60 & 448 & 0.016 & Age** \\
70 & 458 & 0.016 & Gender** \\
80 & 414 & 0.022 & Age* \\
90 & 284 & 0.020 & Gender***, Vehicle Class $(\mathrm{p}=0.06)$ \\
100 & 372 & 0.085 & Age***, Gender**, Vehicle Class $(\mathrm{p}=0.09)$
\end{tabular}


Table 5. Results of the significant multiple regressions models of percent time speeding for each speed limit with age, gender and vehicle class (car or other) as predictor variables, with $10 \mathrm{~km} / \mathrm{hr}$ as the threshold for speeding. Note: ${ }^{*} \mathrm{p}<0.05, * * p<0.01, * * * p<0.001$

\begin{tabular}{l|lll}
$\begin{array}{l}\text { Speed Limit } \\
(\mathrm{km} / \mathrm{h})\end{array}$ & $\mathrm{n}$ & Adjusted $\mathrm{R}^{2}$ & Significant predictors \\
\hline 80 & 414 & 0.015 & Age***, Gender*, Vehicle Class* $^{* *}$ \\
100 & 372 & 0.048 & Age $^{* *}$, Gender**
\end{tabular}

Table 6. Results of the significant multiple regressions models of percent time speeding for each speed limit with age, gender and vehicle class (car or other) as predictor variables, with $15 \mathrm{~km} / \mathrm{hr}$ as the threshold for speeding. Note: ${ }^{*} \mathrm{p}<0.05, * * \mathrm{p}<0.01, * * * \mathrm{p}<0.001$

\begin{tabular}{l|lll} 
Speed Limit $(\mathrm{km} / \mathrm{h})$ & $\mathrm{n}$ & Adjusted $\mathrm{R}^{2}$ & Significant predictors \\
\hline 60 & 448 & 0.020 & Age*** \\
80 & 414 & 0.026 & Age*, Vehicle Class* \\
90 & 284 & 0.014 & Age*, Gender* \\
100 & 372 & 0.067 & Age***, Gender***
\end{tabular}

